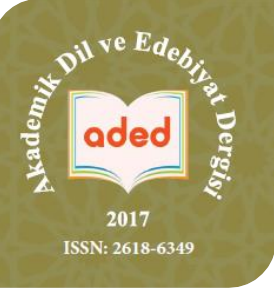

\section{Esra YAVUZ}

Dr., Atatürk Üniversitesi / Türkiye esra.yavuz@atauni.edu.tr

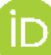

https://orcid.org/0000-0001-5798-5232

\section{Akademik Dil ve Edebiyat Dergisi}

Journal of Academic Language and Literature Cilt/Volume: 5, Sayı/Issue: 2, Ağustos/August 2021

\section{Kazak Türkçesinde Sıfat-Fiillerin Zaman Değerleri Üzerine}

On Tense Values of Verbal Adjectives in Kazakh Turkish

Araştırma Makalesi/Research Article

Geliş Tarihi/Received: 31.05.2021

Kabul Tarihi/Accepted: 09.08.2021

Yayım Tarihi/Published: 30.08 .2021

\title{
Atıf/Citation
}

YAVUZ, E. (2021). Kazak Türkçesinde Sıfat-Fiillerin Zaman Değerleri Üzerine. Akademik Dil ve Edebiyat Dergisi, 5 (2), 951-969. https://doi.org/10.34083/akaded.945992

YAVUZ, E. (2021). On Tense Values of Verbal Adjectives in Kazakh Turkish. Journal of Academic Language and Literature, 5 (2), 951-969. https://doi.org/10.34083/akaded.945992

\section{$\checkmark$ iThenticate}

Bu makale iThenticate programıyla taranmıştır.

This article was checked by iThenticate. 


\section{Öz}

Göreceli bir kavram olan zaman, felsefeden başlamak üzere felsefe temelinde doğmuş bütün bilim dalları için araştırma sahası hâline gelmiştir. Zaman, dil açısından incelendiğinde gerçek zaman ve fiil zamanı olmak üzere iki grupta incelenmektedir. Fiillerin çekim ekleri vasıtasıyla geçmiş, gelecek, şimdiki vb. zaman karşılıkları olduğu gibi sıfat-fiil eklerinin de zaman değerleri vardır. Bu zaman değerleri ekin ihtiva ettiği zaman değerlerinin dışında işlevsel ve anlamsal açıdan incelendiğinde farklı zaman değerlerini de ifade edebildiği bilinmektedir. Çalışmada, Kazak edebî metinlerinden hareketle sıfat-fiil eklerinin hangi zaman değerlerini karşıladığı işlevsel-anlamsal açıdan incelenmeye çalışılmıştır.

Kazak gramerlerinde tespit edilen sınıflandırmalardan farklı olarak çalışmada, sıfatfiillerin zaman değerleri işlevsel-anlamsal açıdan ele alınmıştır. Sıfat-fiiller incelenirken bir sıfatfiil ekinin birden fazla zamana gönderme yaptığı da göz önünde bulundurularak her sıfat-fiil ekinin altında hangi zaman değerine sahip olduğu örneklerle ortaya koyulmuştur. Ayrıca, çalışmada sıfat-fiil eklerinin zamanla kalıplaşarak isim ve sıfat türetme işlevi kazanması nedeniyle örneklerde geçen fiil + sıfat-fiil yapısının sözlüklerde madde başı olarak yer alıp almamasına da özellikle dikkat edilmiştir. Böylece çalışma için sıfat-fiil eklerinin kalıplaşmadığı, yani temel işlevini kaybetmediği örnekler seçilmeye çalışılmıştır.

Anahtar Kelimeler: Kazak Türkçesi, zaman, sıfat-fiil, fiil, sıfat, zaman değeri, işlev.

\section{Abstract}

Tense, which is a relative concept, has been a research area in all branches of science that are based on philosophy. In terms of language, tense is examined in two groups as absolute tense and verb tenses. Verbs have tense equivalents such as past, future, present and so on through inflections and verbal adjective suffixes also have tense values. It is known that these tense values can also express different tense values when examined functionally and semantically, apart from the tense values that an inflection includes. In the study, the tense values to which verbal adjectives suffixes correspond were examined in functional and semantical terms based on Kazakh literary texts.

Unlike the classifications determined in Kazakh grammar books, the tense values of the verbal adjectives were discussed in functional and semantical terms. While examining the adjective-verbs, considering that a verbal adjective suffix corresponds to two or more tenses, the tense value of each verbal adjective suffix was demonstrated with examples. In addition, due to the fact that the verbal adjective suffixes become stereotyped over time and gain the function of deriving nouns and adjectives, special attention was paid to whether the verb+verbal-adjective structure mentioned in the examples is included in the dictionaries as entries. Therefore, the examples including the verbal adjectives suffixes that did not become stereotyped, that is, did not lose their basic function were chosen.

Keywords: Kazakh Turkish, tense, verb, verbal adjective, time value, function 


\section{Giriş}

Zaman kavramı ilk olarak felsefe alanında, ardından felsefenin bir alt kolu olan dil felsefesinde tartışılmaya başlanmıştır. Dil felsefesinin bir parçası olan dilbilimin ise ayrı bir bilim dalı olarak kabul edilmesiyle birlikte zaman kavramı dilbiliminin de konusu hâline gelmiştir.

İlk Çağ felsefecilerinden başlayarak günümüze kadar zaman kavramı hakkında birçok görüş ortaya atılmış, böylelikle zamanın niteliğiyle ilgili sorulara verilen cevaplarda ortak bir perspektife sahip olunamamıştır. Felsefe, bilindiği üzere bütün bilimlerin temelini oluşturur. Felsefenin tartışma konularından biri olan zaman kavramı da günümüzde neredeyse bütün bilim alanlarıyla ilişki içerisindedir.

Geniş bir araştırma alanına sahip olan, tanımlaması zor bir soyut kavram olan zaman, dilbilimsel açıdan gerçek zaman (time) ve fiil zamanı (tense) olmak üzere iki grupta incelenmektedir.

"Gerçek zaman (time), durmadan akıp gider, basit gibi görünse de uzay gibi sınırsız bir boyuta sahiptir ve dildeki temel zamansal yönelim noktası konuşmacının zamanı ile konuşma zamanıdır (şimdi).” (Smith, 2007, s. 420).

Fiil zamanı (tense) kavramını genel olarak tanımlamak gerekirse eylemin, konuşma ile konuşmada açıklanan durum veya olay arasındaki zamansal ilişkisini ifade eden bir kategoridir (Bussmann, 2006, s. 1182). Fiil zamanı (tense), süreç olarak gerçek zamandan farklıdır. Fiil kipleri cümlenin zamanını belirler. Zamansal ilişkiler ifade edilirken zaman, dilin gösterdiği süre açısından düşünülür, bu yüzden de dilbilimciler genel anlamda zaman kavramını tanımlarken süre-zaman açısından zaman çizelgesini esas almaktadır (Whorf, 1957, s. VIII). Zaman çizelgesi ise geçmiş, şimdiki ve gelecek zaman olarak ele alınmaktadır (Michaelis, 2006, s. 1). Ancak bunlar zamanı tam olarak ifade etmekte yetersiz kalmaktadır.

Bir dili anlambilim açısından ele aldığımızda fiil zamanlarında kaymalar gerçekleşebilmekte, yani fiil zaman ekleri temel işlevleri dışında farklı anlamlar üstlenerek kullanılabilmektedir (Yaman, 1999, s. 7).

Cümlede fiil kiplerinin zaman değerleri olduğu gibi sıfat-fiil eklerinin de zaman değerleri bulunmaktadır. Yani sıfat-fiilli yan cümleler de temel cümle içerisinde geçmiş, geniş/şimdiki, gelecek zaman değerlerine sahiptir. Sıfat-fiilli yan cümlelerin zaman değerleri işlevsel, yapısal ve anlamsal özellikleri bakımından temel cümleye veya söylenilen zamana göre farklılık teşkil etmektedir. Ayrıca sıfat-fiil eklerinde de kip eklerinde olduğu gibi zaman kaymaları söz konusu olabilmektedir.

Zaman kaymasının söz konusu olduğu ekler Kazak gramerlerinde değişken/belirsiz zaman olarak ele alınmaktadır. Çalışmada öncelikle Kazak gramerlerinde sıfat-fiillerin zaman değerlerine göre sınıflandırmasına yer verilmiştir. 
Eklerde oluşabilecek zaman kaymaları da dikkate alınarak sıfat-fiil ekleri zaman değerleri açısından işlevsel ve anlamsal olarak ele alınmıştır.

\section{Sıfat-Fiillerin Zaman Değerleri}

Fiil kök ve gövdelerine doğrudan eklenen fiilimsiler, fiillerin isim, sıfat veya zarf türlerine dönüşmüş şekillerini ifade eder. Eklendiği fiil kök ve gövdelerini sıfata dönüştüren ekler sıfat-fiil ekleridir. Sıfat-fiil (Kaz. esimşe, Rus. priçastiye, İng. participle, Alm. partizip, participium, Fr. participe) terimini Zeynep Korkmaz Gramer Terimleri Sözlüğ̈̈'nde şu şekilde tanımlamaktadır: "Sayı ve şahsa bağlı fiil çekimine girmeyen, fakat aldığı eklerle fiilin zamana bağlı olarak taşıdığ sıfatlaştırdığından kendisinde sıfat ve fiil niteliklerini birleştiren fiil şekli." (1992, s. 132).

Kazak gramerlerinde ilk olarak Axmet Baytursınulı 1915 yılında yayımladığı Til Qural II adlı kitabında sıfat-fiillerden bahsetmiş ve sıfat-fiiller için esimşe terimini kullanmıştır. Kazak gramerinde sıfat-fiil eklerinin zaman değerleri konusunda farklı görüşler vardır. Axmet Baytursınulı'ndan itibaren yapılmış bazı sınıflandırmalar aşağıda yer almaktadır.

Axmet Baytursınulı tarafindan hazırlanan Til Qural II adlı çalışmada sıfat-fiiller zaman değerlerine göre şu şekilde sınıflandırılmaktadır:

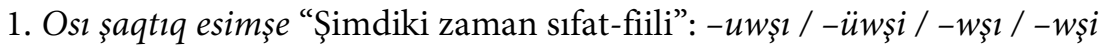

2. Ötken şaqtıq esimşe "Geçmiş zaman sıfat-fiili": -ğan / -gen / -qan / -ken

3. Uyğarındı esimşe "Değişken zaman sıfat-fiili": -atın / -etin / -ytın / -ytin (1992, s. $251 ; 2013$, s. 185$)$.

Ismet (Smet) Kenesbayev tarafından hazırlanan Qazaq Tili adlı çalışmada sıfatfiiller zaman değerlerine göre şu şekilde sınıflandırılmaktadır: ken

1. Priçastiye proşedşego vremeni "Geçmiş zaman sıfat-fiili”: -ğan / -gen / -qan / -

2. Priçastiye buduşçe-perehodnogo vremeni "Gelecek-geçişli zaman sıfat-fiili (Belirsiz gelecek zaman)": -atın / -etin / -ytın / -ytin

3. Priçastiye buduşçego vremeni "Gelecek zaman sıfat-fiili”: -ar / -er / -r; -mas / mes / -bas / -bes / -pas / -pes (1939, s. 53-54).

Mäwlen Balaqayev tarafından hazırlanan Qazaq Tiliniñ Grammatikası adlı çalışmada sıfat-fiiller zaman değerlerine göre şu şekilde sınıflandırılmaktadır:

1. Ötken şaqtıq esimşe "Geçmiş zamanlı sıfat-fiil”: -ğan / -gen / -qan / -ken

2. Awıspalı şaqtıq esimşe "Değişken zamanlı sıfat-fiil": -atın / -etin / -ytın / -ytin 
3. Keler şaqtıq esimşe "Gelecek zamanlı sıfat-fiil": -ar / -er / -r; -mas / -mes / bas / -bes / -pas / -pes (1940, s. 52-53).

Ğali Begaliyev ve Nığmet Sawranbayev tarafından hazırlanan Qazaq Tiliniñ Grammatikası adlı çalışmada sıfat-fiiller zaman değerlerine göre şu şekilde siniflandirılmaktadir:

1. Ötken şaq "Geçmiş zaman”: -ğan / -gen / -qan / -ken

2. Awıspalı keler (ötken) şaq “Değişken gelecek (geçmiş) zaman”: -atın / -etin / ytin / -ytin

3. Keler şaq "Gelecek zaman": -ar / -er / -r; -mas / -mes / -bas / -bes / -pas / pes (1948, s. 102-103).

Ädil Axmetov, K. Jünisbekova ve Fawziya Orazbayeva tarafından hazırlanan Qazirgi Qazaq Tiline Arnal̆̆an Jattı̆̆uwlar: Morfologiya adlı çalışmada sıfat-fiiller zaman değerlerine göre şu şekilde sınıflandırılmaktadır:

1. Ötken şaq "Geçmiş zaman": -ğgan / -gen / -qan / -ken

2. Awıspalı şaq "Değişken zaman": $-a,-e,-i$

3. Keler şaq "Gelecek zaman": -ar / -er / -r; -mas / -mes / -bas / -bes / -pas / pes

4. Maqsat "Maksat": -maq / - mek / -baq / -bek / -paq / -pek

5. Dă̆dılı "Belirsiz": -atın / -etin / -ytın / -ytin; -uwşı / -üwşi / -wşı / -wşi (1998, s. $140-141)$.

Seytjapar Arpabekov tarafından hazırlanan Qazaq Tili adlı çalışmada sıfat-fiiller zaman değerlerine göre şu şekilde sınıflandırılmaktadır:

1. Ötken şaq "Geçmiş zaman”: -ğan / -gen / -qan / -ken; -atın / -etin / -ytın / ytin

2. Osı şaq "Şimdiki zaman": -atın / -etin / -ytın / -ytin

3. Keler şaq "Gelecek zaman": -ar / -er / -r; -mas / -mes / -bas / -bes / -pas / pes; -maq / - mek / -baq / -bek / -paq / -pek (2004, s. 50-53).

Fawziya Orazbayeva, Gulğayza Sağidolda, Balqiya Qasım, vd. tarafından hazırlanan Qazirgi Qazaq Tili adlı çalışmada sıfat-fiiller zaman değerlerine göre şu şekilde sınıflandırılmaktadır:

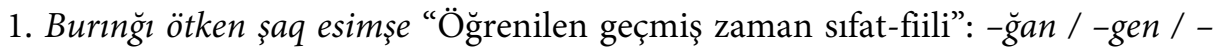
qan / -ken

2. Dağdılı ötken şaq esimşe "Belirsiz geçmiş zaman": -atın / -etin / -ytın / -ytin 
3. Boljaldı keler şaq esimşe "Tahmini gelecek zaman sıfat-fiili": -ar / -er / -r; -mas /-mes / -bas / -bes / -pas / -pes

4. Maqsat mändi keler şaq esimşe "Niyet ifadeli gelecek zaman sifat-fiili": -maq / -mek / -baq / -bek / -paq / -pek; -maqşı / -mekşi / -baqşs / -bekşi / -paqşı / -pekşi (2005, s. 339-340).

Şäbiken Käribayulı Bekturov tarafından hazırlanan Qazaq Tili (Leksika, Fonetika, Morfologiya, Sintaksis) adlı çalışmada sıfat-fiiller zaman değerlerine göre şu şekilde sinıflandirilmaktadir:

1. Ötken şaqtıq esimşe "Geçmiş zamanlı sıfat-fiil”: -ğan / -gen / -qan / -ken

2. Awıspalı şaqtıq esimşe "Değişken zamanlı sıfat-fiil": -atın / -etin / -ytın / -ytin

3. Keler şaqtıq esimşe "Gelecek zamanlı sıfat-fiil”: -ar / -er / -r (2006, s. 127-128)

Şaqaman Irısgül Bektemirqızı tarafından hazırlanan Qazaq Tili Sözderinin Türlenim Jüyesi men Qızmeti adlı çalışmada sıfat-fiiller zaman değerlerine göre şu şekilde sınıflandırılmaktadır:

1. Burınğı ötken şaq “Öğrenilen geçmiş zaman”: -ğan / -gen, -qan / -ken

2. Awıspalı ötken şaq "Değişken geçmiş zaman”: -atın / -etin, -ytın / -ytin

3. Boljaldı keler şaq “Tahminî gelecek zaman”: -ar / -er / -r; -mas / -mes, -bas / -bes, -pas / -pes

4. Maqsattı keler şaq "Niyet ifadeli gelecek zaman”: -maq / -mek, -baq / -bek, paq / -pek (2008, s. 90).

Ibırayım Mamanov tarafından hazırlanan Qazirgi Qazaq Tili adlı çalışmada sıfatfiiller zaman değerlerine göre şu şekilde sınıflandırılmaktadır:

1. Ötken şaq esimşe "Geçmiş zaman sıfat-fiili”: - ğan / -gen, -qan / -ken

2. Dă̆glılı esimşe "Belirsiz zaman sıfat-fiili": -atın / -etin, -ytın / -ytin

3. Niyet esimşe "Niyet ifadeli sıfat-fiil": -maq / -mek, -baq / -bek, -paq / -pek; maqşı/ -mekşi, -baqşı / -bekşi, -paqşı / -pekşi

4. Osı şaq esimşe "Şimdiki zaman sıfat-fiili": -uwşı / -üwşi / -wşı / -wşi (2010, s. 114-136).

Seyilbek İsayev tarafından hazırlanan Qazaq Tili adlı çalışmada sıfat-fiiller zaman değerlerine göre şu şekilde sınıflandırılmaktadır:

1. Ötken şaq esimşe “Geçmiş zaman sifat-fiili”: -ğan / -gen / -qan / -ken; -atın / etin / -ytın / -ytin 
2. Boljaldı keler şaq esimşe "Tahmini gelecek zaman sıfat-fiili”: -ar / -er / -r; -mas /-mes / -bas / -bes / -pas / -pes

3. Maqsattı keler şaq esimşe "Niyet ifadeli gelecek zaman sıfat-fiili": -maq / -mek / -baq / -bek / -paq / -pek (2013, s. 85-86)

Kazak gramerlerinde yapılan bu ve benzeri çalışmalarda yer alan sınıflandırmaların yanı sıra bu çalışmada sıfat-fiiller zaman değerleri açısından şu şekilde sınıflandırılmıştır:

1. Geçmiş zaman sıfat-fiilleri

2. Gelecek zaman sifat-fiilleri

3. Geniş zaman sıfat-fiilleri

Ancak zaman başlıkları altında işlevsel ve anlamsal olarak sıfat-fiilleri değerlendirmek güç olacağından her sıfat-fiil ekinin altında hangi zaman değerini karşıladığı örnekleriyle belirtilmiştir.

Sıfat-fiil ekleri zamanla eklendiği fiille kalıplaşarak isim veya sıfat türetme işlevi kazanmıştır. Bu durumdaki kelimeler ise bilindiği üzere artık sözlüklerde jaz-uwşı > jazuwşı "yazar", ayır-maqşı > ayırmaqşı “ayrıca, özellikle”, öt-ken > ötken "geçmiş”, keler > keler "gelecek" örneklerinde olduğu gibi madde başı olarak yer almaktadır. Bu durumda bu kelimeleri sıfat-fiil bahsi içerisinde ele almak doğru olmayacağından sıfatfiille ilgili çalışmalarda bu hususa dikkat etme gerekliliği ortaya çıkmaktadır. Bu yüzden çalışmada bu duruma dikkat edilerek sıfat-fiil eklerinin kalıplaşmadığı, yani temel işlevini kaybetmediği örnekler seçilmeye çalışılmıştır.

\section{1. /-ğan/, /-gen/, /-qan/, /-ken/}

/-ğan/, /-gen/, /-qan/, /-ken/ eki Kazak gramerlerinde burınğı ötken şaq “öğrenilen geçmiş zaman”, ötken şaq “geçmiş zaman” sıfat-fiil eki olarak ele alınmaktadır. Ancak bu sıfat-fiil ekinde zaman kaymaları söz konusudur. Bu ek hem geçmiş zaman hem de geniş zaman sıfat-fiili işlevinde kullanılmaktadır.

\subsubsection{Geçmiş zaman işlevi}

\begin{tabular}{|l|l|}
\hline $\begin{array}{l}\text { Bir eldiñ şetine kelip, jerge tüsken dändi } \\
\text { terip jep jürip, torğay bir küni balalardiñ } \\
\text { tuzağına tüsedi. (Qasqabasov, 2011/2, s. } \\
\text { 17-18) }\end{array}$ & $\begin{array}{l}\text { "Bir memleketin sinırına geldiğinde, } \\
\text { yere düşmüş tohumları toplayıp yiyerek } \\
\text { gezerken serçe, bir gün çocukların } \\
\text { tuzağına düşer.” }\end{array}$ \\
$\begin{array}{l}\text { Mäselen, bir adamdı söz qıluwğa alsaq, } \\
\text { ya ol adamnıñ istegen isin, aytqan sözin }\end{array}$ & $\begin{array}{l}\text { "Örneğin, bir insandan bahsederken ya } \\
\text { o insanın çalıştı̆̆ı işi, söylediği sözü }\end{array}$ \\
\hline
\end{tabular}




\begin{tabular}{|c|c|}
\hline $\begin{array}{l}\text { äweze qılıp söyleymiz, ya tulğa-turpatın, } \\
\text { keskinin, körkin aytıp, pernesin äliptep } \\
\text { söyleymiz, ya bolmasa ol adamniñ istegen } \\
\text { isteriniñ, öziniñ jaqsı-jaman bolğanının } \\
\text { mänisin, sebebin teksere, bayımdap } \\
\text { söyleymiz. (Baytursinov, 2003, 16) }\end{array}$ & 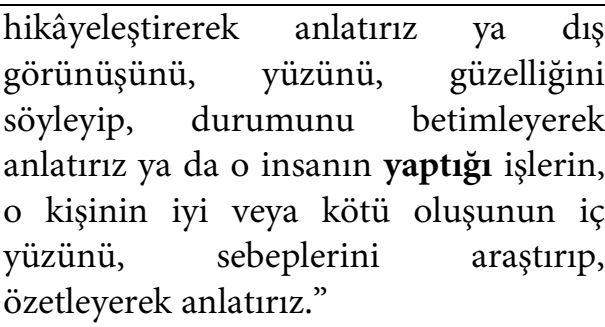 \\
\hline $\begin{array}{l}\text { Äytpese jarıq düniyedegi bir kündik } \\
\text { qonaqtarğa, pendeşilikti perde tutqan } \\
\text { äldekimderge meniñ arız-muñımnıñ } \\
\text { qajeti qanşa?! (Äşimulı, 2014/1, s. 11) }\end{array}$ & $\begin{array}{l}\text { "Ayrıca dünyanın bir günlük misafirleri, } \\
\text { iradesizliği perdelemiş kimseleri için } \\
\text { benim isteğimin bir önemi var mı?!" }\end{array}$ \\
\hline
\end{tabular}

\subsubsection{Geniş zaman işlevi}

Jer betindegi mäwelep ösken ă̆aş ta, qultırğan äsem gülder, jayqalıp turğan ösimdikterdiñ japıraqtarı şıjığan ıstıqtıñ saldarınan sarğayıp solıptı. (Qasqabasov, 2011/1, s. 83)

Osılay ölim awzinan qalğan adamnıñ ömirge degen quştarliğı bölke boladı. (Älimulı, 2014, s. 21)

Aytıs degen qazaqtardıñ aybını, Umıttırar qan juttırğan qayğını. (Ürkimbayulı, 2014, s. 9)
"Yeryüzündeki meyve veren ağaç da çiçek açan güzel çiçekler, kıpırdayan bitkilerin yaprakları [da] artan sıcaklık nedeniyle sararip soldu."

\section{2. /-atın/, /-etin/, /-ytın/, /-ytin/}

/-atın/, /-etin/, /-ytın/, /-ytin/ eki Kazak gramerlerinde uyğarındı esimşe, awıspalı ötken şaq "belirsiz geçmiş zaman"; dağdılı şaq "belirsiz zaman"; os ş̧aq "şimdiki zaman" sıfat-fiil eki olarak ele alınmaktadır. Bu sıfat-fiil ekinde de zaman kaymaları söz konusudur ve bu ek geçmiş, gelecek, geniş zaman sıfat-fiili işlevinde kullanılmaktadır.

\subsubsection{Geçmiş zaman işlevi}




\begin{tabular}{|c|c|}
\hline 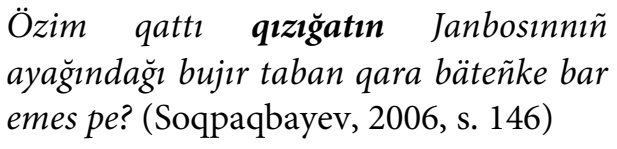 & $\begin{array}{l}\text { "Benim çok beğendiğim Janbosı'nın } \\
\text { ayağındaki eğri büğrü tabanlı kara çizme } \\
\text { vardı değil mi?" }\end{array}$ \\
\hline $\begin{array}{l}\text { Äkesimen birge stsenariyin Oljas } \\
\text { Süleymanov jazatın "Atameken" fil'min } \\
\text { tüsirdi. (Äşimul, } 2014 / 2, \text { s. } 15)\end{array}$ & $\begin{array}{l}\text { "Ağabeyi ile birlikte senaryosunu Olcas } \\
\text { Süleymanov'un yazdığı 'Atameken' } \\
\text { filmini yaptı." }\end{array}$ \\
\hline $\begin{array}{l}\text { Klastıñ işine qam kirpişten jumbazday } \\
\text { salğan qazaqı peşke jağatın otını-jıluwı } \\
\text { joq qamıs, jıñ̆ğl bıqsıp tütindep } \\
\text { közimizdi uwday aşıtadı. (Sädibekul, } \\
2013, \text { s. 5) }\end{array}$ & $\begin{array}{l}\text { "Sınıfın içine pişmemiş kerpiçten } \\
\text { özensizce yapılmış Kazak sobasında } \\
\text { yaktığı odun -sıcaklığı olmayan kamış, } \\
\text { lgın ağacı- için için yanarak tütüp } \\
\text { gözümüzü sızlatıyor." }\end{array}$ \\
\hline
\end{tabular}

\subsubsection{Gelecek zaman işlevi}

\begin{tabular}{|c|c|}
\hline $\begin{array}{l}\text { Bol'şevikterdiñ miltı̆̆ına birewdi qarsı } \\
\text { qoymasa, munday bolatının äwelde-aq } \\
\text { "Alaşorda" bastıqtarı sezgen. (Seyfullin, } \\
\text { 1977, s. 119) }\end{array}$ & $\begin{array}{l}\text { "Bolşeviklerin silahlarına kimse karşı } \\
\text { koymazsa böyle olacağını en başından } \\
\text { Alaşorda liderleri hissettiler." }\end{array}$ \\
\hline $\begin{array}{l}\text { - Aqbala jür. Ol sözi qiyalşıl jigit qoy: } \\
\text { bolmaytın isti boldıram dep, keyde } \\
\text { urınğa şabatını bar. Sözdi täwir köredi, } \\
\text { dep jımıyıp qoyğan. (Aymawıtov, 2013, s. } \\
\text { 217) }\end{array}$ & $\begin{array}{l}\text { “- Akbala yürü! O çok hayalperest bir } \\
\text { delikanlı: 'Olmayacak işi olduracağım!' } \\
\text { diye bazen çabalıyor. Konuşmayı } \\
\text { seviyor, diye gülümsedi.” }\end{array}$ \\
\hline $\begin{array}{l}\text { Baydan keletin päleni erteñ körip } \\
\text { alarmız. (Aqaşeva, 2007, s. 73) }\end{array}$ & $\begin{array}{l}\text { "Zenginden gelecek belayı yarın } \\
\text { göreceğiz." }\end{array}$ \\
\hline
\end{tabular}

\subsubsection{Geniş zaman işlevi}

Kökeyimnen ketpeytin awll jaqqa

Ușip ketkim kelip tur qarliğaş bop.

(Nurğaliyev, 2015, s. 4)

"Aklımdan çıkmayan köye doğru

Uçup gidesim geliyor kırlangıç olup.” 


\begin{tabular}{|l|l|}
\hline $\begin{array}{l}\text { Onan “Aldımızda jaqın jerde qonatın el } \\
\text { bar ma?”- dep suraydı. (Qasqabasov, } \\
\text { 2012, s. 16) }\end{array}$ & $\begin{array}{l}\text { “Ona: 'Bize en yakın yerde konaklayan } \\
\text { halk var mı?' diye soruyor. }\end{array}$ \\
\hline $\begin{array}{l}\text { Qurmannin "Kiyikbay", "Nayza” dep } \\
\text { atalınatın eki ruwı. (Soqpaqbayev, 2006, } \\
\text { s. 119) }\end{array}$ & $\begin{array}{l}\text { "Kumanların Kiyikbay ve Nayza diye } \\
\text { adlandırılan iki boyu (var)." }\end{array}$ \\
\hline
\end{tabular}

\section{3. /-ar/, /-er/, /-r/}

/-ar/, /-er/, /-r/ eki Kazak gramerlerinde keler şaq “gelecek zaman”, boljaldı keler şaq "tahminî gelecek zaman” sıfat-fiil eki olarak değerlendirilmektedir. Bu sıfat-fiil ekinde de zaman kaymaları görülebilmektedir. Bunun neticesinde bu ek gelecek ve geniş zaman sıfat-fiili işlevinde kullanılmaktadır.

\subsubsection{Gelecek zaman işlevi}

\begin{tabular}{|c|c|}
\hline $\begin{array}{l}\text { Berdiqojanıñ bul saparda öz köşin nıq } \\
\text { senimmen bastap kele jatqan sebebi, ol } \\
\text { osıdan bir ay şaması burın qasına bes-altı } \\
\text { joldas ertip, jurt şolıp, barar jerin belgilep } \\
\text { qaytqan. (Jumadilov, 2010, s. } 11 \text { ) }\end{array}$ & $\begin{array}{l}\text { "Berdikoja'nın bu seferi çok güvenli bir } \\
\text { şekilde yöneterek geliyor olmasının } \\
\text { sebebi, o bundan yaklaşık bir ay önce } \\
\text { yanına beş altı yoldaş alıp, yurdu } \\
\text { inceleyip, gideceği yeri belirleyerek geri } \\
\text { dönmüş." }\end{array}$ \\
\hline $\begin{array}{l}\text { Otarşıl patşalıqtıñ aları da az emes, orıs } \\
\text { qalalarınan senin alariñ da az emes. } \\
\text { (Müsirepov, 2003, s. 11) }\end{array}$ & $\begin{array}{l}\text { "Sömürgeci hükümdarlığın alabileceği } \\
\text { (yer) de az değil, Rus şehirlerinden senin } \\
\text { alabileceğin (yer) de az değil." }\end{array}$ \\
\hline $\begin{array}{l}\text { Bul künde qırıq toğızda meniñ jasım, } \\
\text { Qamaldıñ buzar kezim taw men tasın, } \\
\text { Keşegi sentyabr'diñ bazarında, } \\
\text { Köterdim elüw bir put kirdiñ tasın. } \\
\text { (Şolaq, 2014, s. 65) }\end{array}$ & $\begin{array}{l}\text { "Bugün kırk dokuz oldu benim yaşım, } \\
\text { Kalesini yıkacak çağım dağ ile taşın, } \\
\text { Geçen eylül ayının pazarında, } \\
\text { Kaldırdım elli bir put }{ }^{1} \text { kirli taşın.” }\end{array}$ \\
\hline
\end{tabular}

\footnotetext{
${ }^{1}$ Put (<Rus. Пуд): 16,3804964 kilogramlık Rus ağırlık ölçüsü birimi.
} 


\subsubsection{Geniş zaman işlevi}

Eske ustar jayt, eki tom da ortaq asqaralı roman işinde bolatını äri bir kitap turğısındağı mazmun tutastığın saqtap qalatını. (Amantay, 2010, s. 13)

Oy teñizinde maltı̆̆a bergenşe, ekewimizdin sol birge ötkizgen künderimiz ben jıldarımız jayında, bälkim, birewler üşin önege bolar ömrimiz jayında tüygenderimdi qă̆azğa nege tüsirip körmeske degen oy kelgende quwanıp ketkenim ras. (Äşimulı, 2014/2, s. 5)

Bögde adamdarğa közderi şekeley şatınap, buta şaynar azuwların aq köbik arasında qayrasa da, äli de sabırmen boyın salğan. (Altay, 1998, s. 19)
"Akılda kalan durumu, iki cildi de eşit büyüklükteki roman içinde olması hem de bir kitap ölçütündeki içerik bütünlüğünü korumasıydı."

"Düşünce denizinde engellenince, 'İkimizin birlikte geçirdiği günler ve yıllar hakkında, belki, birileri için örnek olan ömrümüz hakkında biriktirdiklerimi kâğıda niçin yazmiyorum?' düşüncesi aklıma gelince mutlu olduğum doğrudur.”

"Yabancı insanlara gözlerini dikip, çalı ssıran dişlerini ağzının köpükleri arasında keskinleştirmesine rağmen hâlâ sabırla boyun eğiyormuş."

\section{4. /-mas/, /-mes/, /-bas/, /-bes/, /-pas/, /-pes/}

/-mas/, /-mes/, /-bas/, /-bes/, /-pas/, /-pes/ eki Kazak gramerlerinde keler şaq "gelecek zaman”, boljaldı keler şaq "tahminî gelecek zaman” sıfat-fiil eki olarak değerlendirilmektedir. Ancak bu sıfat-fiil ekinde zaman kaymaları görülebilmektedir. Bunun neticesinde bu ek gelecek ve geniş zaman işlevi dışında geçmiş zaman sıfat-fiili işlevinde kullanılmaktadır.

\subsubsection{Geçmiş zaman işlevi}

Şı̆̆anbaydiñ özi kiymes kiyimin kiygizip, özi minbes jüyrigin mingizip, jumsap otırğan alatuyağı. Ol sağan nege bersin, desedi awıl adamı. (Älimbayev, Qaliulı, Ospan, Üsenbayev, 2013, s. 93)

Tă̆l birde: "Qaradan xan şıqqanın körgen emespin. Kötere almas şoqparı beline baylamas bolar" degen sözdi de
"Şı̆̆anbay'ın kendi giymediği kıyafeti giydirip, binmediği koşucu atına bindirip, harcayıp oturan serserisi. O sana niye versin, diyorlar köylüler.”

"Bunun dışında: 'Halk arasından han çıktığını görmemiştim. Kaldıramadığın sopayı beline bağlayamazsın." sözü de dikkatini çekmiş." 


\begin{tabular}{|c|c|}
\hline $\begin{array}{l}\text { qulaqqağıs etken. (Q1rğızbayev, 2013, s. } \\
\text { 82) }\end{array}$ & \\
\hline $\begin{array}{l}\text { Dawrıqpay, dañ̆gaza quwmay Soltüstik } \\
\text { Qazaqstan oblısınıñ äkimi Tayır } \\
\text { Mansurov memlekettik tildi oqıtuw men } \\
\text { üyretüwdi aytıp bolmas biyik dengeyge } \\
\text { köterdi, qalay rıyza bolmassıñ! (Ämirbek, } \\
\text { 2015, s. 192) }\end{array}$ & $\begin{array}{l}\text { "Bağırmadan, çă̆ırmadan Kuzey } \\
\text { Kazakistan bölgesinin valisi Tayır } \\
\text { Mansurov, devlet dilinin öğrenimi ve } \\
\text { öğretimini görülmemiş yüksek bir } \\
\text { seviyeye çıkardı, nasıl memnun } \\
\text { olmazsınız!" }\end{array}$ \\
\hline
\end{tabular}

\subsubsection{Gelecek zaman işlevi}

\begin{tabular}{|c|c|}
\hline $\begin{array}{l}\text { Bul Marks pen Leninniñ kommunistik } \\
\text { ideologiya jönindegi ölmes teoriyasınıñ } \\
\text { eñ ayqın, eñ körnekti jalğası. (Esenjanov, } \\
\text { 2014, s. 309) }\end{array}$ & $\begin{array}{l}\text { "Bu, Marks ile Lenin'in Komünist } \\
\text { ideoloji hakkındaki ölmeyecek } \\
\text { teorisinin en açık, en somut devamıdır." }\end{array}$ \\
\hline $\begin{array}{l}\text { Ekinşi birewler közin oyıp tastaydı } \\
\text { nemese tügel köterip äketedi de, köz } \\
\text { körmes, qulaq estimes jerdegi tanıstarına } \\
\text { aparıp sıylaydı, ne kerek, erte me, keş pe, } \\
\text { adam qolınan opat boladı. (Raxmatulla, } \\
2015, \text { s. } 144)\end{array}$ & $\begin{array}{l}\text { "Diğerleri gözlerini oyar veya tamamen } \\
\text { çıkarır ve gözün görmeyeceği, kulağın } \\
\text { işitmeyeceği yerdeki tanıdıklarına } \\
\text { götürüp hediye eder, kısacası, er ya da } \\
\text { geç insanların elinde ölür." }\end{array}$ \\
\hline $\begin{array}{l}\text { Sodan beri Sayram men Märtöbe qazaq } \\
\text { kökiregine bayă̆ı zamannıñ oralmas } \\
\text { elesi, öşpes ökinişi, jazılmas jarası bop } \\
\text { ornadı. (Kekilbayulı, 1999, s. } 277 \text { ) }\end{array}$ & $\begin{array}{l}\text { "O zamandan beri Sayram ile Mertöbe } \\
\text { Kazakların yüreğine eski zamanın geri } \\
\text { dönmeyecek hayali, bitmeyecek } \\
\text { pişmanlığı, iyileşmeyecek yarası olarak } \\
\text { yerleşti." }\end{array}$ \\
\hline
\end{tabular}

\subsubsection{Geniş zaman işlevi}

Beyimbet qazaqtıñ sovet ädebiyetinin körki, tawilmas qazınası deymiz. (Aqaşeva, 2007, s. 143)

"Beyimbet'e 'Kazak Sovyet edebiyatının süsü, bulunmaz bir hazinesi' diyoruz.” 


\begin{tabular}{|c|c|}
\hline $\begin{array}{l}\text { Qutılmas qurıqqa tüskenin bilip endi } \\
\text { munan şığuwdın jolını izdegen. } \\
\text { (Abdraxmanov, 2010, s. 189) }\end{array}$ & $\begin{array}{l}\text { "Kurtuluşu olmayan bir kemende } \\
\text { yakalandığını anlayınca artık bundan } \\
\text { çıkmanın yolunu aramış." }\end{array}$ \\
\hline $\begin{array}{l}\text { İnisiniñ jañă̆ı "kegim" degen arılmas } \\
\text { armanın tüsingende Baqtıgul osınday tas } \\
\text { qamawdıñ bar tınıstı tarıltqan kesir } \\
\text { keskinderin eske aldı. (Äwezov, } 2014 \text { /2, } \\
\text { s. 93) }\end{array}$ & $\begin{array}{l}\text { "Erkek kardeşinin demin 'intikamım' } \\
\text { dediği bitmek bilmez arzusunu } \\
\text { anladığında Baktıgul, böyle bir taş } \\
\text { hapishanenin nefesini kesen kötü } \\
\text { görünüşünü hatırladı." }\end{array}$ \\
\hline
\end{tabular}

\section{5. /-uwş1/, /-üwşi/, /-wş1/, /-wşi//}

Kazak gramerlerinde /-uwş1/, /-üwşi/, /-wş1/, /-wşi/ eki bazen osı şaq esimşe "şimdiki zaman sıfat-fiili”, dağdılı şaq "belirsiz zaman” olarak ele alınmakta bazen ise sıfat-fiil ekleri arasında değerlendirilmemektedir. İşlevsel olarak ele alındığında bu ek geniş zaman sıfat-fiil eki olarak kullanılmaktadır.

\subsubsection{Geniş zaman işlevi}

\begin{tabular}{|c|c|}
\hline $\begin{array}{l}\text { Bir küni Särsenbaydın üyine eski jolmen } \\
\text { oqı̆̆an, düniyede bilmegen närselerim joq } \\
\text { dep duğa qıluwşı bir şala nadan molla } \\
\text { kelip qondı. (Duwlatov, 2003, s. 10) }\end{array}$ & $\begin{array}{l}\text { “Bir gün Sersenbay’ın evinde, eski usul } \\
\text { okumuş, "Dünyada bilmediğim şey } \\
\text { yok!” deyip dua eden yarı cahil bir molla } \\
\text { gelerek konakladı." }\end{array}$ \\
\hline Bul köktemdi qarsı aluwşı aprel', & \\
\hline Să̆ınıp tur quşaq jayıp bükil el. & "Bu baharı karşılayan nisanı, \\
\hline $\begin{array}{l}\text { (Qazaq SSR Ğılım Akademiyası, 1963, s. } \\
\text { 26) }\end{array}$ & Özlüyor kucak açarak bütün halk.” \\
\hline $\begin{array}{lcc}\text { Talasuwşı balalardıñ birine, } & \text { qane, } \\
\text { qalağanıñdı suwırıp al } & \text { deydi. } \\
\text { (Soqpaqbayev, 2006, s. 128) } & \end{array}$ & $\begin{array}{l}\text { "İtiraz eden çocuklardan birine, 'Hadi, } \\
\text { kalanını çekip al!' diyordu." }\end{array}$ \\
\hline
\end{tabular}

\section{6. /-maq/, /-mek/, /-baq/, /-bek/, /-paq/, /-pek/}

/-maq/, /-mek/, /-baq/, /-bek/, /-paq/, /-pek/ eki Kazak gramerlerinde maqsat şaq "maksat”, maqsat mändi keler şaq "niyet ifadeli gelecek zaman”, maqsattı keler şaq "niyet ifadeli gelecek zaman", niyet esimşe "niyet ifadeli sifat-fiil" olarak değerlendirilmektedir. Bu ek gelecek zaman sıfat-fiili işlevinde kullanılmaktadır. 


\subsubsection{Gelecek zaman işlevi}

\begin{tabular}{|c|c|}
\hline 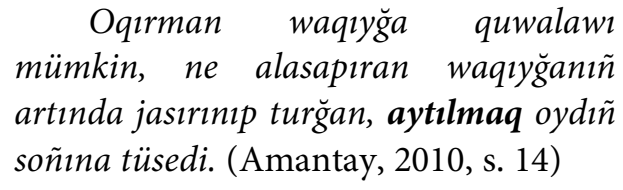 & $\begin{array}{l}\text { "Okuyucu olayı takip edebilir yahut } \\
\text { çileli dönem olayının ardında saklanan, } \\
\text { söylenecek düşüncenin peşine düşer” }\end{array}$ \\
\hline $\begin{array}{l}\text { Jaña sekretar'diñ osı eki jıraq awdanğa } \\
\text { barmaq boluwı Qasımovtı şın } \\
\text { quwantqanday. (Äwezov, 2014/3, s. 82) }\end{array}$ & $\begin{array}{l}\text { "Yeni sekreterin bu iki uzak ilçeye } \\
\text { gidecek oluşu Kasımov'u gerçekten } \\
\text { sevindirmiş gibi." }\end{array}$ \\
\hline $\begin{array}{l}\text { Bujır beti odan sayın jawar bulttay } \\
\text { tünerip kete bermek oyı, kenet äldenesin } \\
\text { umıtqanday soñına qayrılğanda, quyrı̆̆ın } \\
\text { bulğandata ere bergen kökqasqa qanşıqtı } \\
\text { tewip kep qalğan. (Qumarova, 2012, s. } \\
\text { 23) }\end{array}$ & $\begin{array}{l}\text { "Pürüzlü yüzünü, gittikçe yağmur } \\
\text { bulutu gibi toplanıp gidiverecek bir } \\
\text { fikri, ansızın bir şeyi unutmuşçasına } \\
\text { geriye döndürdüğü sırada kuyruğunu } \\
\text { sallayarak giden yılkı atına dişisi } \\
\text { tepivermişti." }\end{array}$ \\
\hline
\end{tabular}

\section{7. /-maqşı/, /-mekşi/, /-baqşı/, /-bekşi/, /-paqşı/, /-pekşi/}

/-maqş1/, /-mekşi/, /-baqş1/, /-bekşi/, /-paqş1/, /-pekşi/ eki Kazak gramerlerinde maqsattı keler şaq "niyet ifadeli gelecek zaman", niyet esimşe "niyet ifadeli sıfat-fiil”" eki olarak değerlendirilmektedir. $\mathrm{Bu}$ ek gelecek zaman sifat-fiili işlevinde kullanılmaktadır.

\subsubsection{Gelecek zaman işlevi}

At äkelmekşi bolğan bawırı onı suwrqqa tomp, talıp jığıllp jatqan jerinen tawip aladı. (Äwezov, 2014/1, s. 413)
"Atı getirecek olan kardeşi, onu soğuktan donup, bayılarak düştüğü yerde buluverdi."
Munı estigende Eskeldiniñ kökşildew ottı janarınan joğarıraqta qas-qabaq emes, endi-endi qanatın jazıp jiberip uşıp ketpekşi küykentay attı qustın özi oturğanday türi özgerip ketti. (Dospanbetov, 2016, s. 159)
"Bunu işitince Eskeldi'nin mavimsi ateşin daha yukarısında yüzü değil, yeni yeni kanadını açarak uçup gidecek ala doğan adlı kuş oturuyormuş gibi yüzü değişiverdi." 
Balanı ispen emes, sözben, ülgimen emes, aqılmen üyretpekşi adam sorlı ğoy. (Aymawitov, 2003, s. 9)
“Çocuğu işle değil sözle, örnekle değil öğütle eğitecek insan, ne kadar da zavallı."

\section{Sonuç}

Çalışmada, Kazak Türkçesinde sıfat-fiiller zaman değerleri işlevsel ve anlamsal açıdan incelenmiştir. Bu inceleme sırasında elde edilen bulgular şu şekildedir:

Kazak edebî metinlerinde kullanım sıklığı açısından en çok karşımıza çıkan sıfatfiil eklerinden biri /-ğan/, /-gen/, /-qan/, /-ken/ ekidir. Kazak gramerlerinde burınğ ötken şaq "öğrenilen geçmiş zaman”, ötken şaq "geçmiş zaman” sıfat-fiil eki olarak ele alınan bu ek, işlevsel ve anlamsal açıdan sadece geçmiş zaman sıfat-fiil eki değil, aynı zamanda geniş zaman sıfat-fiil eki işlevinde de kullanıldığg tespit edilmiştir.

Kazak gramerlerinde uyğarındı esimşe, awıspalı ötken şaq "değişken geçmiş zaman"; dağdılı şaq "belirsiz zaman"; osı şaq "şimdiki zaman" sıfat-fiil eki olarak ele alınan ve Kazak edebî metinlerinde kullanım sıklığı açısından en çok karşımıza çıkan /-atın/, /-etin/, /-ytın/, /-ytin/ sıfat-fiil ekinin işlevsel ve anlamsal açıdan geçmiş ve geniş zaman işlevleri dışında gelecek zaman sıfat-fiili işlevinde de kullanıldığı tespit edilmiştir.

Kazak gramerlerinde keler şaq "gelecek zaman", boljaldı keler şaq "tahminî gelecek zaman" sıfat-fiil eki olarak değerlendirilen /-ar/, /-er/, /-r/ sıfat-fiil ekinin gelecek zaman işlevi dışında geniş zaman sıfat-fiili işlevinde kullanıldığı görülmektedir.

Türkiye Türkçesi gramerinde olduğu gibi Kazak Türkçesinde de /-ar/, /-er/, /-r/ sıfat fiil ekinin olumsuzu olarak kullanılan ve Kazak gramerlerinde keler şaq "gelecek zaman", boljaldı keler şaq "tahminî gelecek zaman" sıfat-fiil eki olarak değerlendirilen /-mas/, /-mes/, /-bas/, /-bes/, I-pas/, /-pes/ sıfat-fiil ekinin gelecek zaman sıfat-fiili işlevi dışında geçmiş ve geniş zaman sıfat-fiili işlevinde de kullanıldığı tespit edilmiştir.

Kazak gramerlerinde osı şaq esimşe "şimdiki zaman sıfat-fiili", dağdılı şaq esimşe "belirsiz zaman sıfat-fiili" olarak ele alınan /-uwşı/, /-üwşi/, /-wşı/, /-wşi/ sıfat-fiil eki geniş zaman sıfat-fiil eki olarak kullanılmaktadır.

Kazak gramerlerinde maqsat şaq "maksat", maqsat mändi keler şaq "niyet ifadeli gelecek zaman", maqsattı keler şaq "niyet ifadeli gelecek zaman", niyet esimşe "niyet ifadeli sıfat-fiil" olarak değerlendirilen /-maq/, /-mek/, /-baq/, /-bek/, /-paq/, /-pek/; maqsattı keler şaq "niyet ifadeli gelecek zaman", niyet esimşe "niyet ifadeli sıfat-fiil" olarak ele alınan /-maqşı/, /-mekşi/, /-baqșı1, /-bekşi/, /-paqșı1, /-pekși/ sıfat-fiil eklerinin işlevsel olarak gelecek zaman sıfat-fiili işlevinde kullanıldığı görülmektedir. 
Kazak gramerindeki her sıfat-fiil ekinin Türkiye Türkçesindeki karşıllğg işlevine ve anlamına göre değişiklik göstermektedir. Sıfat-fiil eklerinin işlevsel ve anlamsal zaman değerleri ele alındığında her sıfat-fiil ekinin metnin bağlamına göre karşlığının bulunması önemlidir. Buna göre çalışmada her sıfat-fiil ekinin bir zaman değeri olduğu, ayrıca bir sıfat-fiil ekinin farklı zaman değerlerini de karşılayabildiği örnekler bağlamında incelenerek tespit edilmiştir. 


\section{Kaynakça}

Abdraxmanov, M. (2010). Sağım Jıldar. Almatı: Abzal-Ay Baspası.

Altay, A. (1998). Qır men Qala Xikayaları. Almatı: Sanat Baspası.

Amantay, D. (2010). Qarqaralı Basında: Roman, Povest', Äñgimeler, Esseler, Öleñder. Almatı.

Aqaşeva, S. S. (2007). Sarıarqa Sañlağı. Almatı: QR BĞM Ortalıq Ğılımiy Kitapxanası Baspaxanası.

Arpabekov, S. (2004). Qazaq Tili (Anıqtamalıq). Almatı: Däwir Baspası.

Axmetova, Ä., Jünisbekova, K., \& Orazbeyava, F. (1998). Qazirgi Qazaq Tiline Arnalğan Jattığuwlar: Mofologiya. Almatı: Respublikalıq Baspa Kabineti.

Aymawitov, J. (2003). Aqbilek. Almatı: Atamura Baspası.

Aymawitov, J. (2013). Jüsipbek Aymawttov Şığarmaları: Romandar. Almatı: El-Şejire Baspasi.

Älimbayev, M., Qaliulı, S., Ospan, S., \& Üsenbayev, B. (2013). Aldar Köse Xikayaları. Almatı: Balalar Ädebiyeti Baspası.

Älimulı, A. (2014). Ğumır-Dariya. Almatı: Arna Baspası.

Ämirbek, K. (2015). Söyle Deseñ, Söyleyin. Almatı: “Qarataw KB” JŞS, Dästür Basbası. Äşimulı, A. (2014/1). ... Jan Bölek. Almatı: Arna Baspası.

Äşimulı, A. (2014/2). Mayranı̃ Äni. Almatı: Arna Baspası.

Äwezov, M. (2014/1). Şığarmalarınin Elüw Tomdıq Jıynağı: Maqalalar, Äñgimeler, Awdarmalar, P'esalar (1921-1925). T. 2. (Red.. M. Qul-Muxammed, A. Särinjipov) Almatı: "Däwir" "Jibek Jolı" Baspası.

Äwezov, M. (2014 /2). Şığarmalarınıñ Elüw Tomdıq Tolıq Jıynağı: Povester (1927-1929).

T. 5. (Red. M. Qul-Muxammed jäne A. Särinjipov). Almatı: "Däwir" "Jibek Jolı" Baspasi.

Äwezov, M. (2014/3). Şığarmalarını̃̃ Elüw Tomdıq Tolıq Jıynağı: Roman, Roman Josparı, Derekter (1959-1961). T. 39. (Red. M. Qul-Muxammed jäne A. Särinjipov). Almatı: "Däwir" "Jibek Jolı" Baspası.

Balaqayev, M. (1940). Qazaq Tiliniñ Grammatikası. Alma-Ata: Qazaq Memleket Baspasi.

Baytursınov, A. (2003). Ädebiyet Tanıtqış: Zerttew men Öleñder. Almatı: Atamura Baspası. 
Baytursınulı, A. (1992). Til Tağılımı. Almatı: Ana Tili Baspası.

Baytursınulı, A. (2013). Altı Tomdıq Şı̆̆armalar Jıynă̆ı: Til Qural. T. 3. (Qurastırğan: R. Saxıbekqızı) Almatı: El-Şejire Baspası.

Begaliyev, Ğ., \& Sawranbayev, N. (1948). Qazaq Tiliniñ Grammatikası. Almatı: Qazaqtıñ Memlekettik Oquw Quraldar Baspası.

Bektemirq1zı, Ş. I. (2008). Qazaq Tili Sözderiniñ Türlenim Jüyesi men Qızmeti. Pavlodar: Eko Baspası.

Bekturov, Ş. K. (2006). Qazaq Tili (Leksika, Fonetika, Morfologiya, Sintaksis). Almatı: Atamura Baspasi.

Bussmann, H. (2006). Dictionary of Language and Linguistics. (Translate: G. Trauth and K. Kazzazi) London: Routledge.

Dospanbetov, U. (2016). Abılaydıñ Aq Tuwı. T. 1. Almatı: Tomiris 21 Baspası.

Duwlatov, M. (2003). Oyan, Qazaq!. Almatı: Atamura Baspası.

Esenjanov, X. (2014). Ängimeler men Maqalalar. Almatı: Merekeniñ Baspalar Üyi.

İsayev, S. M. (2013). Qazaq Tili. Almatı: Öner Baspası.

Jumadilov, Q. (2010). Tozaq Otı: Xikayattar, Äñgimeler, Sır-Suxbat, Oy-Tolğamdar. Almatı: Qazığurt Baspası.

Kekilbayulı, Ä. (1999). On Eki Tomdıq Şı̆̆armalar Jıynă̆ı. T. 3. Almatı: Ölke Baspası.

Kenesbayev, S. (1939). Qazaq Tili (Uçebnik Kazahskogo Yazıka v Russkoy Sredney Şkole). Almatı: Qazaq Memlekettik Baspası.

Korkmaz, Z. (1992). Gramer Terimleri Sözlüğ̈̈u. Ankara: Türk Dil Kurumu Yayınları.

Qasqabasov, S. (Ed.) (2011/1). Babalar Sözi: Xaywanattar Tuwralı Ertegiler. T. 73. Astana: Foliant Baspası.

Qasqabasov, S. (Ed.) (2011/2). Babalar Sözi: Qıyal-Ğajayıp Ertegiler. T. 74. Astana: Foliant Baspasi.

Qasqabasov, S. (Ed.) (2012). Babalar Sözi: Tarixiy Añzdar. T. 88. Astana: Foliant Baspasi.

Qazaq SSR Ğılım Akademiyası. (1963). Aqındar Jırı: Qazirgi Xalıq Poeziyası. (Ed. S. Bekmuxamedova, L. Moskviçeva). Alma-Ata: Qazaq SSR Ğılım Akademiyasınıñ Baspas1.

Q1rğızbayev, Ö. (2013). Sozaq Qasireti. Almatı: Ana Tili Baspası.

Qumarova, Ş. (2012). Ğasır Nurı. Almatı: An Arıs Baspası. 
Mamanov, İ. (2010). Qazirgi Qazaq Tili. Pavlodar: S. Torayğırov Atındağı Pavlodar Memlekettik Universiteti Baspası.

Mäwlenov, S. (2013). Şığarmaları: Öleñder (1938-1958). T. 1. Almatı: An Arıs Baspası.

Michaelis, L. A. (2006). Time and Tense. The Handbook of English Linguistics (s. 1-24), Ed. B. Aarts and A. McMahon. Oxford: Blackwell.

Müsirepov, Ğ. (2003). Ulpan - Roman. Almatı: Atamura Baspası.

Nurğaliyev, Ö. (2015). Soğıstıñ Soñğı Jazı. T. 2. Almatı: Jazuwşı Baspası.

Orazbayeva, F., Sağidolda, G., Qasım, B., Qobılanova, A., Esenova, Q., İsabekova, U., Köpebayeva, J. (2005). Qazirgi Qazaq Tili: Oquw Quralı. Almatı: PrintS Baspası.

Raxmatulla, J. (2015). Dala Tolğawı. Almatı: Sözdik-Slovar' Baspası.

Sädibekulı, A. (2013). Qaraşa Üydiñ Kelini. Almatı: Qaynar Baspası.

Seyfullin, S. (1977). Tar Jol, Tayğaq Keşüw. Almatı: Jazuwşı Baspası.

Smith, C. S. (2007). Tense and Temporal Interpretation. Lingua. 117. 419-436.

Soqpaqbayev, B. (2006). Meniñ Atım Qoja. Balalıq Şaqqa Sayaxat (Povester). Almatı: Balawsa Baspası.

Şolaq, B. (2014). Şığarmaları: Änderi, Öleñ-Jırları. Estelikter, Maqalalar, Añız. (Qurastırğan: B. Xabdina). Almatı: Rux BG Baspası.

Ürkimbayulı, İ. (2014). Dala Jırı. Almatı: Xantäñiri Baspası.

Whorf, B. L. (1957). Language, Thought and Reality. Cambridge: MIT Press.

Yaman, E. (1999). Türkiye Türkçesinde Zaman Kaymaları. Ankara: Türk Dil Kurumu Yayınları. 